\title{
Initial Career and Work Meanings \\ in Seven European Countries
}

\author{
Rita Claes* \\ University Gent \\ S. Antonio Ruiz Quintanilla \\ Center for Advanced Human Resource Studies \\ New York State School of Industrial and Labor Relations \\ Cormell University \\ Ithaca, NY 14853-3901 \\ Working Paper \#93-11
}

Article accepted for publication in The CAREER DEVELOPMENT QUARTERLY

This paper has not undergone formal review or approval of the faculty of the ILR School. It is intended to make results of Center research, conferences, and projects available to others interested in human resource management in preliminary form to encourage discussion and suggestions. 


\begin{abstract}
The study explores the initial careers of two target groups of youngsters in seven European countries. Career patterns are constructed through cluster analysis on data gathered from the youngsters through a retrospective self-report procedure covering a period of 2:5 years. Six career patterns are identified across countries by the activities taking place (employment, various educational preparations, unemployment, military or civil service) and further described by personal and work-related variables as well as by work meanings and psychological well-being in the second year on the labor market. Some suggestions are given for further research and implications for career counseling, career education, organizational career guidance and development.
\end{abstract}

\title{
Profety ar MARTIN P. CATHERWOCD UERTEY \\ NEY YORK STATE SCHODL

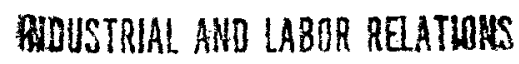


Initial Career and Work Meanings

in Seven European Countries

The transition between school, training, and first full-time employment has become a complex one. Nowadays transition activities may include such diverse activities as additional general education, further vocational programs or stages, specific job training, military or civil service, part-time employment, temporary work, periods of unemployment, counseling and periods of actively searching for work. In addition frequent changes among these activities during the initial career are not exceptional.

The individual's first job, the transitions, and initial career activities can have far-reaching effects on subsequent career development (Leibowitz, Schlossberg, * Shore, 1992) because they constitute a significant part of the work socialization process. Work socialization refers to the over-time interaction of work meanings and work environment that results in accommodation or (mis)matches and corresponding behaviors. Transitions and beginning career activities are important because they shape a person's initial work role development through their impact on work meanings, work related strategies, and behavior patterns. Work meanings developed during this period serve as a framework to asses and evaluate workrelated experiences (Ruiz Quintanilla, 1991).

The present study explores and describes the initial careers of two target groups of youngsters in seven European countries. Given that January 1,1993 marks the date when freedom to choose education, living place, and working place in any of the European countries for any citizen of European Communities' member states got implemented, adds to the value of the study. To be able to predict the impact of such a law, a better understanding of the current situation is needed. Questions like: What are the various educational ways (general education, vocational education, permanent education) utilized to prepare for labor market entry in the different European countries and how frequent are they (Coleman \& Hendry, 1990)? Do career starters follow comparable routes in the different countries, or are the pathways country specific? 
In addition this article explores the relationship between initial career, work meaning development and psychological well-being by analyzing how typical career patterns are related to differences in work meanings (MOW International Research Team, 1987). Of special interest here is the presence of unemployment periods during the beginning of a career, especially for those youngsters who go directly from school into unemployment and consequently miss the experience of the psychological functions of sorking (Banks and Ullah, 1988; O'Brien, 1986; Warr, 1991 ).

Career starters' activities are investigated from the initial period of immediate preparation for a first full-time job and ending with the completion of their second year in the labor market. To study initial careers, a pattern approach is applied. Utilizing a retrospective self-report procedure youngsters list activities held over a period of 2.5 years. The pattern approach emphasizes that transition and early career activities do not operate independently in the course of time, but rather form a pattern. This means that while one activity increases another decreases or while one activity is present another has to be absent. It also means that the order makes a difference. For example, the activities of unemployment, temporary employment, and full-time employment form different patterns if they progress from unemployment via temporary work to full-time employment as opposed to regressing from full-time employment through temporary employment to unemployment. Thus, initial career patterns are defined by the combination of single activities which youngsters have experienced in the period before their first full-time and fully paid employment through their second year in the labor market. The pattern approach uses Ward's (1963) method for hierarchical clustering to identify groups of respondents with the same combination of activities from a certain starting point to a certain ending point. The initial career patterns are identified across countries by activities taking place and further described in terms of personal and work-related variables, and in terms of work meanings and psychological well-being in the second year in the labor market. Method

Participants 
The present study uses data from the international comparative longitudinal Work Socialization of Youth research project (WOSY International Research Group, 1989a). To ensure comparability over the different countries two occupational groups are included in the study:

The office technology group consists of mostly female youth beginning employment in office automation, including word processor operators, typists, teletypists, micro or mini computer operators, clerks; and operators of equipment which classifies, sorts, calculates, summarizes and records data.

The machine operators in production/manufacturing departments in the metal industry are predominantly males, including die casting machine operators, machine moulders, lathe and milling machine operators, machine coremakers, machine tool fitterassemblers, welders, machine flame-cutter operators. The number of the participants per country (thus aggregated over the two occupational groups) are: Belgium 265 , England 335, France 70, Italy 255, Netherlands 115, Portugal 228, and Spain 90. Procedure

Data were collected during two individual interviews. The first interview was scheduled after the youngster was employed for about a year in the first full-time, fully paid job, and the second interview was about one year later. The interviewer completed a standardized interview schedule (WOSY International Research Group, 1989b) with 22 questions covering work personality, work environment, outcomes, and behaviors.

\section{Instruments}

Information on the activities youngsters performed before and during the first two years of their work career were gathered through a retrospective tracing procedure. They were asked: "I would like to know what you have been doing over the past couple of years. Please choose with me for every three-month period what you were doing for most of the time. Check with me also the changes that have occurred since our last conversation". The activity categories used were "Regular work" full-time; "Regular work" part-time; Temporary work; Vocational education; General education; Education (dominant) combined with work; Work (dominant) combined with 
education; Unemployed, looking for work; Unemployed, not looking for work; Military or civil service. Categories for hours (work schedule) were Days; Evenings; Nights; Rotating shift; Split-shift; Four days work week; Flex-time; Any other part-time schedule; Weekend, Saturday or sunday. Finally changes in job title, hierarchical position, firm, industry are documented.

Work meanings were assessed with questions adapted from the Mow International Research Team (1987). For the purpose of this study, they were combined into five indices, all expressed in standardized T-scores: "Work centrality" combines an absolute and relative measure of the centrality or importance working has for individuals; "Intrinsic work orientation" combines the importance rating/ranking of six intrinsic work goals llearning opportunity, interpersonal relations, variety, interesting work, match between abilities and job requirements, autonomy); "Extrinsic work orientation" combines the importance rating/ranking of five extrinsic work goals (promotion, convenient work hours, job security, pay, physical working conditions); "Entitlement orientation" combines four societal norm items which emphasize the entitlement aspect (retraining and reemployment, participation in decision making on work methods, meaningful work, general right to work); "Obligation orientation" combines three societal norm items which focus on the obligation or duty aspect (duty to save portion of income, value boring, dirty, unskilled work, accept monotonous work).

We measured psychological well-being with the 12-item version of the General Health Questionnaire (Goldberg, 1972; Banks 1983). The participants reported on recent daily functioning by answering 12 questions (for example "Been able to concentrate on whatever you're doing", "Been feeling unhappy and depressed") with answer categories: "much less then usual", "less than usual", "same as usual", "more than usual". A Likert scoring with weights 0 through 3 , and then summing over the 12 items, resulted in an index with maximum a score of 36 (high level of complaints, low psychological well-being) and a minimum score of 0 (no complaints, high psychological well-being).

Data Analysis 
The construction of initial career patterns recodes the original more detailed categories of activity as registered in the retrospective self-reports into the following five broader categories, based on the earlier exploratory research (Claes, Ruiz Quintanilla, \& Whitely, 1992): "employed" now combines all kinds of employment like regular full-time work, regular part-time work, temporary work, 'work (dominant) combined with education; "vocational education" now combines vocational education (directly preparing the person for an occupation), and any mixture of education and work with education being dominant; "general education" not aimed at specific occupational preparation; "unemployed" now combines both out of work and looking for work, and out of work and not looking for work; "military or civil service". The five activity categories for ten trimesters were recoded into 50 binary variables as input for Ward's method for agglomerative hierarchical clustering with the squared Euclidian distance as proximity measure. The cluster analysis was performed on 1130 valid cases across countries. The portuguese data became available after the identification through cluster analysis of the initial career patterns. Through multiple discriminant analysis the Portuguese respondents were allocated to the six identified clusters. The number of clusters retained was based on: (a) a large increase of the coefficient between two adjacent steps in the agglomeration schedule; (b) the distribution of respondents over the clusters; (c) a minimum of 90 cases in each cluster; and (d) relevant differential content of the clusters.

To describe the initial careers in terms of work meanings and psychological wellbeing analyses of variance was conducted. Per career pattern the mean and standard deviation on the work meanings and the psychological well-being index are reported; as well as the overall mean and standard deviation on the work meanings and the psychological well-being and the summarized ANOVA results.

\section{Results}

Ward's hierarchical clustering of the five activities during ten trimesters yielded six clusters reaching the technical cluster solution criteria and providing differential content. Below follows an integrated description of the six initial 
career patterns. The patterns are first identified in terms of the nature, the variety, and the sequence of the career activities based on the occurrence of career activities per trimester per cluster. Table 1 gives for each identified cluster the percentages of the five activity categories per trimester. In Table 2 , the six career patterns are described in terms of person-related characteristics (country, occupational group, sex, educational level, age), and work-related characteristics (work schedule, career mobility).

Insert Table 1 about here

Insert Table 2 about here

Finally, the six career patterns are described in terms of work meanings and psychological well-being as established after the second year of labor market experience. To analyze the relation of the six initial career patterns to the work meanings and psychological well-being a series of analyses of variance are conducted. Table 3 lists for each of the six initial career patterns the mean and standard deviation as well as the overall mean and standard deviation for each index, and the summarized analysis of variance results.

Insert Table 3 about here

Pattern $R$ "Employment from the start": Looking at the nature and sequence of the career activities or the trajectories followed, one pattern is special among the six. It is characterized by employment from the start on the labor market with no other activities relevant for its identification. Stabilization of the employment status can be seen as a major objective during the (initial) work career, therefore, this cluster is further used as a reference for the other 
clusters, hence it is called "pattern $R^{\prime \prime}$. About 16.48 of the respondents (N=223) were characterized by employment from the start and quite some stability in job title, hierarchical position, company and industry during the second year as compared to the other respondents. They mainly work day schedules. The reference pattern occured in all of the seven European countries under study (especially frequently in Portugal). Males and females, both occupations, and all educational groups were present although we found respondents having only a primary education slightly over-represented. In general, the reference pattern unites the older respondents, those in average the 21 years-of-age, although there exists quite some heterogeneity in age. This group showed the highest work centrality, as well as both high obligation and entitlement norm orientations. Their psychological wellbeing is around the grand mean.

Pattern 1 "Vocational education to employment": This pattern portrays about one third of all participants $(N=441)$. Youngsters in this pattern were on the average 20 years old and entered their first employment coming from vocational education, eventually via some unemployment to continue with a fairly stable period during their second career year (Table 1). These respondents mainly worked day schedules. In short, this group is characterized by balanced demographics (country, occupational group, sex, educational level). The respondents held average work meaning values and possessed average psychological well-being.

Pattern 2 "Unemployment to employment": For members of this group, work entry was preceded by unemployment both searching and not searching for work. Mainly in Belgium and Italy do youngsters experience this trajectory. Following the experience of unemployment, this group is characterized by a stable career, although having some external mobility as reflected in changes of job title and company occurs. This pattern described about 10.8 percent (N=147) of the participants. Most of them belonged to the office technology group, were female, with a high percentage being college-educated. The average age was 21 years. These youngsters usually work during the day or in split shift. They scored lowest on the extrinsic work orientation at the end of the second year of labor market exposure. 
Their high entitlement orientation combined with a low obligation orientation, and their well-being was the poorest compared to all other groups.

Pattern 3 "Military/civil service and some unemployment to employment": These youngsters fulfil their military or civil service before entering the labor market and this work entry is frequently preceded by unemployment. A total of about 8.6 percent ( $N=117$ ) of the respondents, mainly from Italy and Belgium, shared this specific trajectory. Later, during the second year, their work career was characterized by some change in hierarchical position and by a low external mobility as reflected in company or industry changes. They mainly work split shifts or have a days schedule. The majority of them were males and had a collegeeducation. The average age was 21 years. Participants in this career pattern have the lowest work centrality after two years of labor-force experience compared to the other groups. They show high entitlement scores and the lowest obligation orientation. Besides being low in their intrinsic work orientation, their psychological well-being was also closer to the poor side.

Pattern 4 "Employment to additional training": For 8.2 percent $(N=111)$ of the respondents, the main trend seemed to be increasing dominance of vocational education over plain employment: "Training" here means a combination of education (dominant) and work, such as company training programs. Some go through periods of unemployment. General education and military/civil service become less frequent. In the second year of their career, a change of the company was relatively frequent. They were mostly machine operators less so office technology workers, more males than females, and none of them had a university degree. The average age was 19 years, which makes this group the second youngest. These respondents work mainly during days. They were found in all countries, although especially in France. These participants showed the highest intrinsic work orientation and the highest extrinsic work orientation. They are highly work centered and exhibit the best psychological well-being.

Pattern 5 "General education to employment": This group's trajectory into work was via general education. During their initial work career some were unemployment. 
The mainly English trajectory includes youngsters from both occupational groups, both males and females. The group has the most mobile careers, internally as well as externally, with especially frequent changes in job title, of company and industry. The dominant work schedule is day time. The pattern described about 23.58 $(\mathrm{N}=319)$, of all participants with a near to exclusive share of secondary school educated. The average age was 17 years, which makes it the youngest group. Youth following this path of early career experiences were among those whose extrinsic work orientation was high, while their entitlement orientation was the lowest. There psychological well-being was among the better.

On the positive side it should be noted that at this stage of the career about two years after joining the labor market - none of the initial career patterns ends in unemployment.

\section{Conclusions and Implications}

The pattern approach to describing career development yielded six initial career patterns. Three patterns were about equally frequent in all seven countries and three more "country-specific" ones occured mainly in Belgium, Italy, and England. Thus the most frequent career patterns that youngsters of the two occupational groups followed through the first two years of their work career in seven European countries can be seen as falling into one out of six alternatives or career patterns. Further description of the career patterns in terms of personrelated and work-related characteristics, provides insight in which respondents (country membership, occupatiónal group membership, gender, educational level, age) follow which early career paths and how mobile these careers actually are in terms of promotion and turnover.

Figure 1 summarizes the relationships of the initial career patterns to the work meanings and the psychological well-being outcomes.

Insert Figure 1 about here

Career starters participating in continuous general educational programs 
(pattern 5) prior to the work entry developed higher career mobility (both internal and external) in the second year of their work career and had a better psychological well-being compared to most participants following other pathways in their initial career.

staying longer in general educational programs leads to higher extrinsic work orientations during the second year of the work career compared to immediately entering the labor market with full-time employment duties, or military or civil service before the work entry. The same does not hold true if the educational program serves mainly vocational purposes (pattern 1).

Respondents who switch from work to additional training mainly in form of a vocational company training program (pattern 4) show a high extrinsic work orientation, high work centrality and good psychological well-being.

As discussed above, respondents who have been out of work during the initial transition period from school to work (pattern 2), continue their second year in the labor market in stable employment. Still, their unemployment experience leads to a lower extrinsic work orientation during the second year in the labor market, as well as to poorer psychological well-being. Further these respondents develop a quite unbalanced societal norms orientation characterized by high entitlement and low obligation expectations.

A smooth transition from school to work without big gaps, and continuous full-time employment (pattern R) seems to result in high work centrality, a high obligation orientation, and a high entitlement orientation, as well as average or slightly better well-being.

Finally, those respondents whose initial career includes military or civil service and periods of unemployment show a low work centrality, unbalanced societal norms with low obligation and high entitlement expectations, as well as poor psychological well-being.

Looking at the countries from which longitudinal career development data are analyzed - Belgium, France, England, Italy, the Netherlands, Portugal, and Spain this study dealt with the initial career of youth in North-West and South Europe. 
It is remarkable that, at the start of the single European labor market, these European Communities' member states reflect more similarities than differences if it comes to early careers of their youth.

What are implications of these findings for practitioners in career education, career counseling, and organizational career planning ?

Career counselors should keep in mind the different impact educational programs have dependent on their content (vocational or general) and duration on facilitating work entry, avoiding unemployment experience, and later career progress. They should address these issues in talking to their young clients to assist career preparations' decisions, such as choosing between continuing a more general educational program or enrolling in training programs directly serving certain occupations. Furthermore, since career counselors may be the only channel through which the youngsters themselves can profit from recent research findings (Arnold, 1992) on the early career, they need to expand their knowledge on successful patterns of early work experiences, and help the youngsters translate this information to illustrate critical career choices.

The reported relations of initial career pathways with work meanings are important for organizational career planners because of their link with work motivation and work behavior. During the period of recruiting new organization members - when organizational career development should actually start - the career planner should be sensitive for the origins of the current status of work meanings held by applicants. Given examples for work meanings which partly lie in the early career experiences, include the relationship of early unemployment experience with imbalanced work norm orientations and high extrinsic orientations (importance of pay, job security, good physical working conditions, convenient work hours) or the low work centrality of those with military or civil service experience. Further, the knowledge about (reciprocal) relationships of early work experiences, resulting work meanings and psychological well-being, can help the organizational career planner to develop together with the employee a flexible career plan which strives to harmonize individual goals like self-realization and good psychological health 
and economic objectives of the organization. Let's assume a career counselor has to advise a member of career pattern 4, employees switching from employment to additional training, which as discussed tends to be accompanied by work meanings like higher intrinsic and extrinsic work orientations. Knowing this, the organizational career planner is advised to carefully scrutinize and discuss both job content as well as instrumental outcomes of potential jobs to optimize the fit between motivational functions and job characteristics. 
References

Arnold, J. (1992). From education to job markets. In Fisher, S.L., \& Cooper, C.L. (Eds.), On the move: the psychology of change and transition. (pp. 207-230). New York: John Wiley and Sons.

Banks, M.H. (1983). Validation of the General Health Questionnaire in a young community sample. Psychological Medicine, 13, 349-353.

Banks, M.H., \& Ullah, P. (1988). Youth unemployment in the 1980s: A psychological analysis. Beckenham: Croom Helm.

Claes, R., Ruiz Quintanilla, S.A., \& Whitely, W. (1992). Types de préparation à la vie professionnelle (Career preparation patterns). Revue Internationale de Psychologie Sociale (International Review of Social Psychology), $\underline{5}$ (1), 37-59. Coleman, J.C., \& Hendry, L. (1990). The nature of adolescence. London: Routledge. Goldberg, D.G. (1972). The detection of psychiatric illness by questionnaire. London: Oxford University Press.

Goldberg, D.P., \& Williams, P. (1988). A users quide to the General Health Questionnaire. Windsor: National Foundation for Educational Research. Leibowitz, z.B., Schlossberg, N.K., \& Shore, J.E. (1992). New employees: a career development challenge. In Montross, D.H. and Shinkman, C.J. (Eds.), Career development: theory and practice. (pp. 137-161). Springfield IIl.: C.C. Thomas. MOW International Research Team (1987). The meaning of working. London: Academic Press.

O'Brien, G.E. (1986). Psychology of work and unemployment. Chichester: Wiley \& Sons.

Ruiz Quintanilla, S.A. (1991). Introduction: The meaning of work. In Ruiz Quintanilla, S.A. (Ed.), Special issue on work centrality and related work meanings. The European Work and Organizational Psychologist, 1 (2-3), 81-89. 
ward, J. (1963). Hierachical grouping to optimize an objective function. Journal of the American Statistical Association, 58, 236-244.

Warr, P. B. (1991). Workers without a job. In Warr, P.B. (Ed.), psychology at work. (pp. 335-356). London: Penguin Books.

wOSY International Research Group (1989a). Socializacion laboral del joven : un estudio transnacional (Work socialization of youth: an international study). Papeles del Psicologo (Psychological Papers), 39/40, 32-35.

woSY International Research Group (1989b). Interview schedule of the work Socialization of Youth study. (Report No.1). University Gent Belgium. Department of Sociopsychology of work and organization.

Weissman, M.N., \& Klerman, G.L. (1977). Sex differences and the epidemiology of depression. Archives of General Psychiatry, 34, 98-111. 
Authors' names in alphabetic order. Rita Claes is professor in the Department of Sociopsychology of Work and Organization, University Gent. Address: Henri Dunantlaan 2, 9000 Gent, Belgium. S. Antonio Ruiz Quintanilla is visiting associate professor at the Department of Personnel and Human Resources Studies and the Center for Advanced Human Resource studies, the New York state school of Industrial and Labor Relations, Cornell University. Address: Ives Hall 165 box 393, Ithaca New York 14853-3901. 
Table 1

Percentage of activities per trimester per career pattern

\section{Trimester}

\begin{tabular}{|c|c|c|c|c|c|c|c|c|c|c|}
\hline & & & & & & & & & & \\
\hline Career & 1 & 2 & 3 & 4 & 5 & 6 & 7 & 8 & 9 & 10 \\
\hline Activity & & & & & & & & & & \\
\hline Employed & 83.7 & 82.7 & 98.1 & 89.4 & 99.0 & 96.2 & 97.1 & 96.2 & 93.3 & 92.3 \\
\hline Vocational education & 3.8 & 0.0 & 0.0 & 0.0 & 0.0 & 1.0 & 1.9 & 1.0 & 0.0 & 0.0 \\
\hline General education & 5.8 & 1.9 & 0.0 & 0.0 & 0.0 & 0.0 & 0.0 & 0.0 & 0.0 & 0.0 \\
\hline Unemployed & 6.7 & 6.7 & 1.9 & 1.9 & 1.0 & 1.0 & 1.0 & 2.9 & 5.8 & 4.8 \\
\hline Military/civil service & 0.0 & 8.7 & 0.0 & 0.7 & 0.0 & 1.9 & 0.0 & 0.0 & 1.0 & 2.9 \\
\hline Employed & 8.9 & 2.4 & 3.0 & 8.1 & 40.9 & 90.5 & 94.3 & 90.2 & 85.6 & 85.6 \\
\hline Vocational education & 82.7 & 92.7 & 96.2 & 85.1 & 45.0 & 6.0 & 0.0 & 0.0 & 0.0 & 0.0 \\
\hline General education & 2.2 & 0.5 & 0.3 & 1.1 & 0.3 & 0.3 & 0.5 & 0.5 & 0.5 & 0.5 \\
\hline Unemployed & 6.0 & 4.1 & 0.5 & 5.1 & 13.6 & 2.7 & 2.2 & 1.4 & 3.0 & 2.2 \\
\hline Military/civil service & 0.3 & 0.3 & 0.0 & 0.5 & 0.3 & 0.5 & 3.0 & 7.9 & 10.8 & 11.7 \\
\hline
\end{tabular}




\begin{tabular}{|c|c|c|c|c|c|c|c|c|c|c|}
\hline \multirow[b]{3}{*}{ Activity } & \multicolumn{10}{|c|}{ Trimester } \\
\hline & 1 & 2 & 3 & 4 & 5 & 6 & 7 & 8 & 9 & 10 \\
\hline & & & & & & & & & & \\
\hline Employed & 14.0 & 25.7 & 11.8 & 41.9 & 35.3 & 97.1 & 95.6 & 98.5 & 99.3 & 96.3 \\
\hline Vocational education & 1.5 & 0.0 & 0.7 & 1.5 & 0.7 & 2.2 & 0.0 & 0.0 & 0.0 & 0.7 \\
\hline General education & 0.0 & 0.0 & 0.7 & 0.7 & 0.0 & 0.0 & 0.0 & 0.0 & 0.0 & 0.7 \\
\hline Unemployed & 80.9 & 68.4 & 85.3 & 51.5 & 64.0 & 0.7 & 4.4 & 1.5 & 0.7 & 2.2 \\
\hline Military/civil service & 3.7 & 5.9 & 1.5 & 4.4 & 0.0 & 0.0 & 0.0 & 0.0 & 0.0 & 0.0 \\
\hline Employed & 9.9 & 15.3 & 10.8 & 27.9 & 27.9 & 64.9 & 99.1 & 100.0 & 98.2 & 98.2 \\
\hline Vocational education & 0.0 & 0.9 & 4.5 & 22.5 & 32.4 & 34.2 & 0.9 & 0.0 & 0.0 & 0.9 \\
\hline General education & 2.7 & 0.0 & 0.0 & 0.0 & 0.0 & 0.0 & 0.0 & 0.0 & 0.0 & 0.0 \\
\hline Unemployed & 10.8 & 18.0 & 16.2 & 13.5 & 6.3 & 0.0 & 0.0 & 0.0 & 1.8 & 0.9 \\
\hline Military/civil service & 76.6 & 65.8 & 68.5 & 36.0 & 33.3 & 0.9 & 0.0 & 0.0 & 0.0 & 0.0 \\
\hline
\end{tabular}




\begin{tabular}{|c|c|c|c|c|c|c|c|c|c|c|}
\hline \multirow[b]{3}{*}{ Activity } & \multicolumn{10}{|c|}{ Trimester } \\
\hline & 1 & 2 & 3 & 4 & 5 & 6 & 7 & 8 & 9 & 10 \\
\hline & & & & & & & & & & \\
\hline Employed & 24.5 & 17.9 & 19.8 & 26.4 & 61.3 & 50.9 & 2.8 & 0.9 & 10.4 & 17.0 \\
\hline Vocational education & 23.6 & 41.5 & 40.6 & 39.6 & 14.2 & 47.2 & 94.3 & 94.3 & 84.0 & 78.3 \\
\hline General education & 18.9 & 22.6 & 23.6 & 23.6 & 0.9 & 0.9 & 0.0 & 0.0 & 0.0 & 0.0 \\
\hline Unemployed & 19.8 & 4.7 & 3.8 & 2.8 & 20.8 & 0.9 & 0.0 & 0.0 & 0.9 & 0.9 \\
\hline Military/civil service & 13.2 & 13.2 & 12.3 & 7.5 & 2.8 & 0.0 & 2.8 & 4.7 & 4.7 & 3.8 \\
\hline Employed & 6.9 & 0.3 & 0.7 & 5.3 & 55.3 & 85.9 & 98.0 & 98.4 & 98.7 & 94.7 \\
\hline Vocational education & 1.6 & 1.3 & 0.3 & 3.3 & 9.9 & 7.6 & 1.3 & 1.0 & 0.0 & 1.3 \\
\hline General education & 86.5 & 98.0 & 97.7 & 83.6 & 7.2 & 4.6 & 0.3 & 0.0 & 0.0 & 0.7 \\
\hline Unemployed & 4.9 & 0.3 & 1.3 & 7.9 & 27.6 & 2.0 & 0.3 & 0.3 & 1.3 & 3.0 \\
\hline Military/civil service & 0.0 & 0.0 & 0.0 & 0.0 & 0.0 & 0.0 & 0.0 & 0.3 & 0.0 & 0.3 \\
\hline
\end{tabular}


Table 2

Career patterns in terms of person- and work-related characteristics

\begin{tabular}{|c|c|c|c|c|c|c|}
\hline \multirow[b]{2}{*}{ Person characteristics } & \multicolumn{6}{|c|}{ Career pattern } \\
\hline & $\mathbf{R}$ & 1 & 2 & 3 & 4 & 5 \\
\hline \multicolumn{7}{|l|}{ Country $(8, N=1358)$} \\
\hline Belgium (19.5) & 17.9 & 29.0 & 46.3 & 23.1 & 1.8 & 0.0 \\
\hline France $(5.2)$ & 3.1 & 2.0 & 1.4 & 0.9 & 44.1 & 0.6 \\
\hline England (24.7) & 1.8 & 10.2 & 1.4 & 1.7 & 13.5 & 83.7 \\
\hline Italy $(18.8)$ & 11.2 & 13.6 & 34.7 & 59.8 & 28.8 & 5.3 \\
\hline Netherlands $(8.5)$ & 4.0 & 21.3 & 0.0 & 0.0 & 2.7 & 2.8 \\
\hline Portugal $(16.8)$ & 53.4 & 16.3 & 7.5 & 5.1 & 4.5 & 4.7 \\
\hline Spain $(6.6)$ & 8.5 & 7.5 & 8.8 & 9.4 & 4.5 & 2.8 \\
\hline \multicolumn{7}{|l|}{ Chisq $=1660 \mathrm{df}=30 \mathrm{p} \leq .001$} \\
\hline \multicolumn{7}{|l|}{ Occupation $(8, N=1358)$} \\
\hline Office technology (51.2) & 48.9 & 50.3 & 72.8 & 47.0 & 19.8 & 56.4 \\
\hline Machine operators $(48.8)$ & 51.1 & 49.7 & 27.2 & 53.0 & 80.2 & 43.6 \\
\hline Chisq $=76 \quad d f=5 \quad p \leq .001$ & & & & & & \\
\hline \multicolumn{7}{|l|}{$\operatorname{Sex}(8, N=1358)$} \\
\hline Male $(64.9)$ & 61.0 & 63.7 & 47.6 & 92.3 & 88.3 & 58.9 \\
\hline Female $(35.1)$ & 39.0 & 36.3 & 52.4 & 7.7 & 11.7 & 41.1 \\
\hline Chisq $=91 \quad d f=5 \quad p \leq .001$ & & & & & & \\
\hline
\end{tabular}




\section{Career pattern}

\begin{tabular}{|c|c|c|c|c|c|c|}
\hline Person characteristics & $\mathbf{R}$ & 1 & 2 & 3 & 4 & 5 \\
\hline \multicolumn{7}{|l|}{ Education $(8, N=1241)$} \\
\hline Primary school (3.1) & 9.8 & 1.7 & 2.7 & 2.6 & 4.7 & 0.0 \\
\hline Secondary school $(60.0)$ & 48.6 & 56.6 & 39.5 & 30.8 & 61.7 & 91.9 \\
\hline Some college $(34.0)$ & 35.5 & 38.7 & 54.4 & 65.0 & 33.6 & 6.5 \\
\hline University degree $(2.8)$ & 6.1 & 2.9 & 3.4 & 1.7 & 0.0 & 1.6 \\
\hline Chisq $=264 \quad \mathrm{df}=15 \mathrm{p} \leq .001$ & & & & & & \\
\hline \multicolumn{7}{|l|}{$\begin{array}{l}\text { Age at first interview } \\
(\mathrm{N}=1320)\end{array}$} \\
\hline overall mean $=19.60$ & 21.21 & 19.65 & 21.10 & 21.30 & 18.83 & 17.29 \\
\hline overall $\mathrm{SD}=2.61$ & 2.64 & 2.11 & 2.21 & 1.81 & 2.22 & 1.87 \\
\hline$F=125.45 \quad p \leq .001$ & & & & & & \\
\hline
\end{tabular}

Work characteristics

Work schedule end second

year $(8, \mathrm{~N}=1252$ )

Days (64.5)

$\begin{array}{llllll}62.3 & 61.9 & 44.0 & 31.5 & 73.6 & 86.5\end{array}$

Rotating (9.6)

$\begin{array}{llllll}14.2 & 11.4 & 11.2 & 16.2 & 10.4 & 1.0\end{array}$

split (14.5)

$\begin{array}{llllll}9.9 & 13.2 & 29.1 & 38.7 & 7.5 & 6.8\end{array}$

$\begin{array}{lllllll}\text { Other work schedules }(11.4) & 13.6 & 13.5 & 15.7 & 13.5 & 8.5 & 5.8\end{array}$

Chisq= 186 df $=15 \quad p \leq .001$ 


\section{Career pattern}

Work characteristics

$\mathbf{R}$

1

2

3

4

\section{Changes during second year}

(frequencies of changes in

four trimesters summed and

expressed in \&)

Job title (29.2)

Position (18.7)

Company $(21.6)$

Industry (15.4)
12.222.

14.7

13.8

23.7

28.3

47.6

$12.7 \quad 18.2$

$9.0 \quad 13.1$

29.8

22.4

24.2

$\begin{array}{llll}24.1 & 14.9 & 33.6 & 29.6\end{array}$

$\begin{array}{llll}21.4 & 11.4 & 17.9 & 20.8\end{array}$ 
Table 3

Initial career patterns in terms of work meanings and psychological well-being in the second year on the labor market

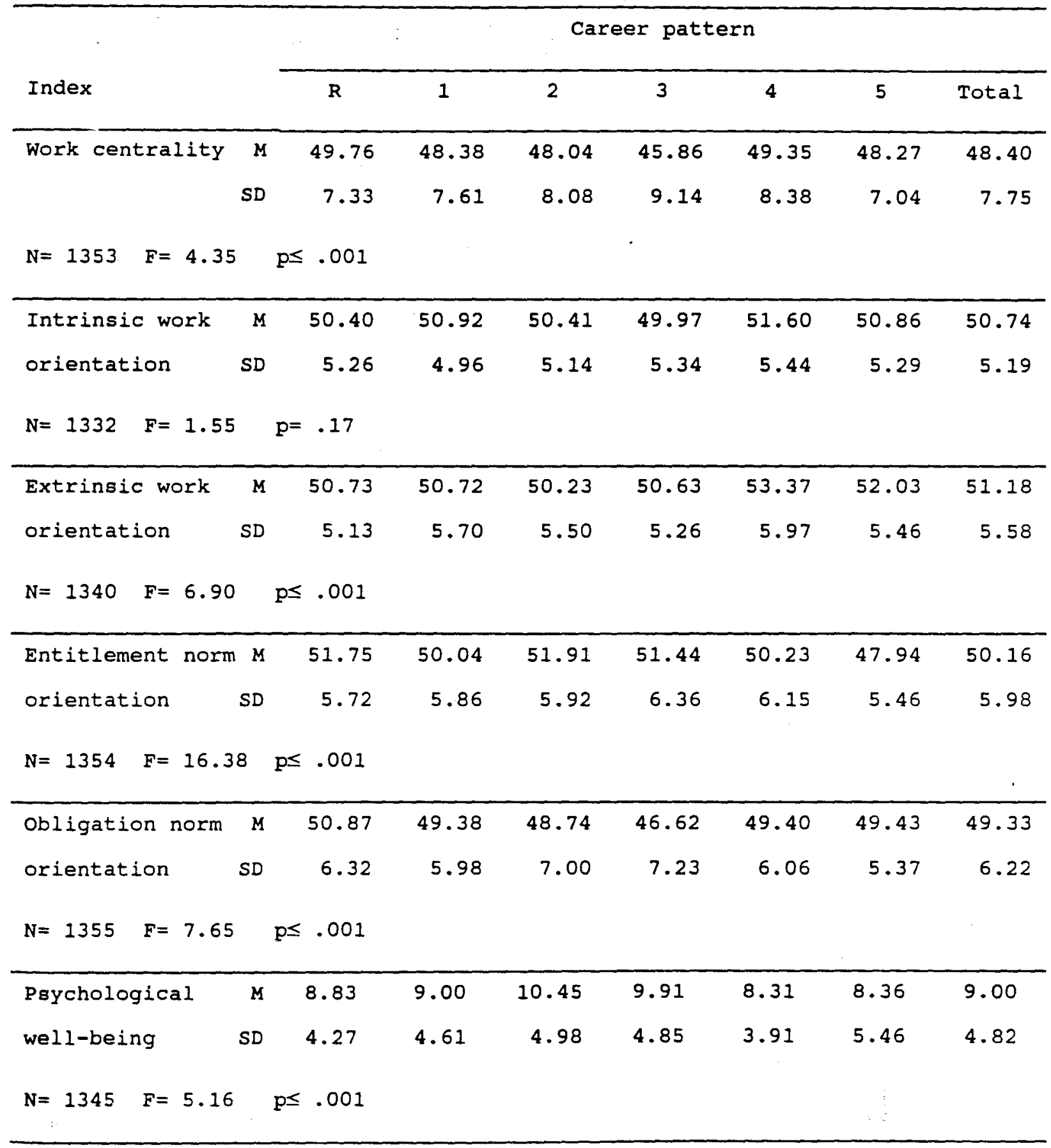


Figure Caption

Fiqure 1. Initial career and work meanings and psychological well-being.

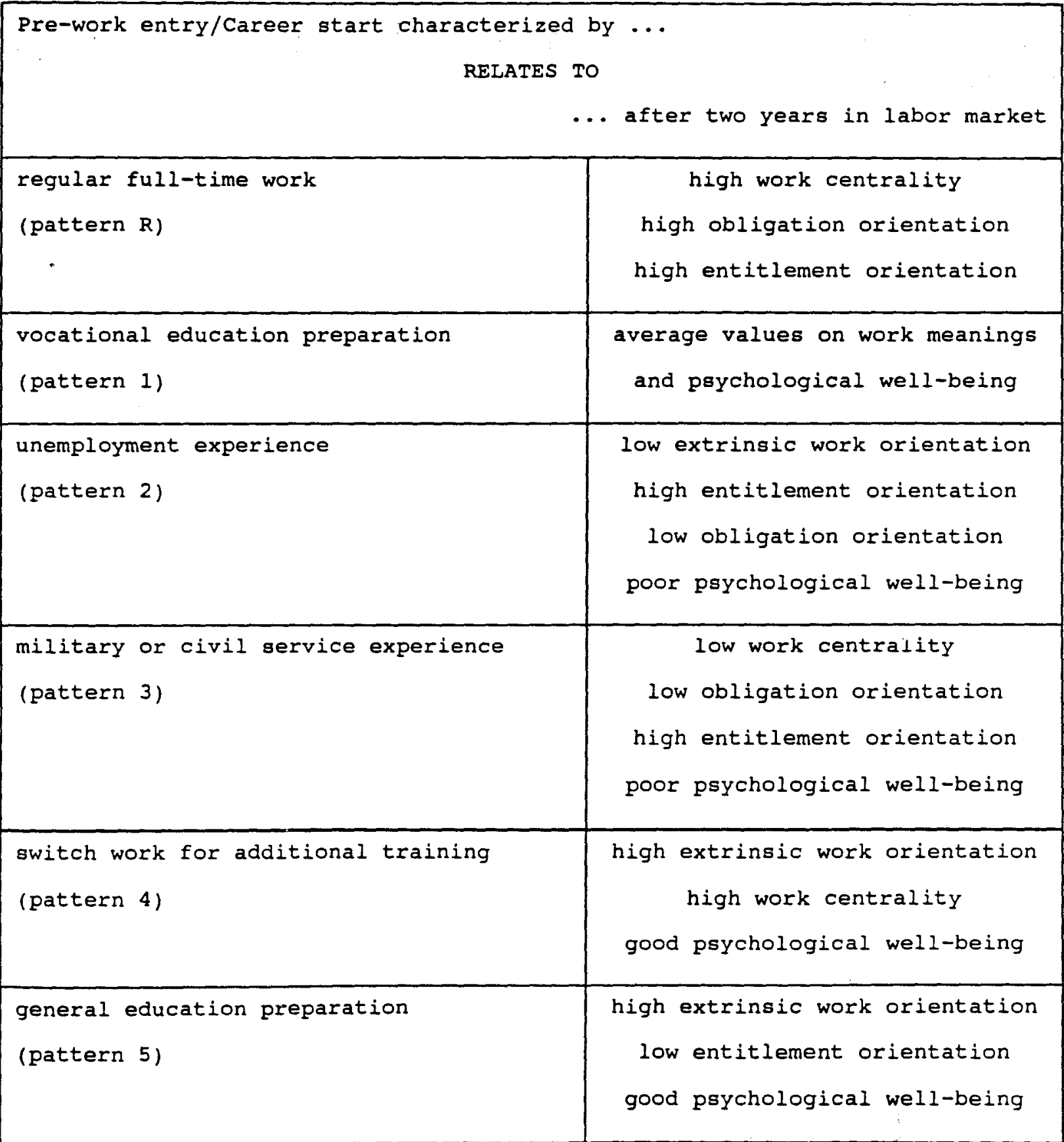

